ISSN: $1130-3743$

\title{
RE-HACER LA EDUCACIÓN: LOS MAPAS DEL DESARROLLO HUMANO
}

\section{Remaking the education: the buman development maps}

\section{Re-faire l'éducation: les mappes du developpement humain}

\author{
Alfonso Fernández Herrería y Gabriel Carmona Orantes \\ Universidad de Granada. Facultad de Ciencias de la Educación. Departamento \\ de Pedagogía. Campus Universitario de Cartuja. 18071 Granada. \\ Correo-e: alfonsof@ugr.es, gcarmona@ugr.es
}

Fecha de recepción: marzo de 2009

Fecha de aceptación definitiva: julio de 2009

Biblid [(1130-3743) 21, 2, 2009, 45-78]

\section{RESUMEN}

En el presente artículo exponemos sobre la base de una crítica a la educación actual, una propuesta de reconstrucción de la concepción de la educación, ampliando su significado en cuanto actividad que hace crecer a la persona, mejora la vida social y la relación con el entorno ecológico. Desde un concepto de educación como desarrollo de lo humano, y, por consiguiente, como aprendizaje a lo largo de toda la vida, los mapas del desarrollo humano son los mapas de la educación. Necesitamos transitar los itinerarios que están representados por estos mapas, enriquecerlos desde una perspectiva humanística y transpersonal, con el deseo de paliar, en lo posible, el malestar existente en la educación. Las esperanzas puestas décadas atrás en ella se han tornado hoy en desencantos, decepciones, incluso en desconfianzas y resentimientos. Las reformas educativas se suceden sin que, al parecer, encontremos vías de solución a nuestros problemas. 
Palabras clave: educación humanística, enfoque transpersonal, antropología educativa, educación como liberación.

\section{SUMMARY}

In this article we present the base of a criticism to actual education, a proposal of reconstruction of the education conception, extending its meaning about the activity which makes the people grow, it improves the society life and the relation with the ecologic environment. From a concept of education like human development, and therefore, as a learning process throughout the whole life, the human development maps are the education maps. We need to walk the itinerary that are represented by these maps and enrich them from the human and transpersonal perspective, wishing to remove, as far as possible, the existing discomfort in education. The hopes that, decades ago, were put on it have become today disenchantments, disappointments, even distrusts and resentments. The education reforms continue without finding, apparently, any solutions to our problems.

Key words: human education, transpersonal approach, educational anthropology, education like liberation.

\section{SOMMAIRE}

Dans le présent article nous exposons, sur la base d'une critique à l'éducation actuelle, une proposition de reconstruction de l'éducation, en élargissant sa signification en tant qu'activité, la quelle fait grandir la personne en soi-même, amélieur la vie social ainsi que la relation avec l'entourage écologique. Partant du concept de l'éducation, comme développement de la personne humaine et, pour autant, comme apprentissage du vécu, les mappes du développement humain sont ceux-ci de l'éducation. Nous avons besoins de parcourir les chemins qui sont représentés par ces mappes, en les enrichissants dès une perspective humanistique et transpersonnelle, avec le désir d'apaiser dans la mesure du possible, le malaise existant dans l'éducation. L'espoir mise en celle-ci arriérèrent, s'est détournée aujourd'hui sur le désenchantent, la déception, la méconfiance ainsi que sur le ressentiment. Les réformes éducatives se sont succédées sans que, au paravent, nous puisons trouver les vois de la réponse à notre problème.

Mots clés: éducation de l'humanité, approche transpersonnelle, anthropologie éducative, éducation comme libération.

\section{INTRODUCCIÓN}

Necesitamos repensar la educación, ampliar su significado en cuanto actividad que hace crecer a la persona, mejora la vida socioeconómica y sus relaciones con 
la naturaleza. Cuando se hace la pregunta acerca de lo que es la educación, es habitual contestar que educar es humanizar, desarrollar lo humano a lo largo de toda la vida, lo que hace referencia necesaria a un proceso de construcción y a las etapas del mismo. Santos Rego decía que la educación es un "proceso de desarrollo humano" (1995, 39). Sin embargo, a pesar del valor de estas concepciones la práctica educativa resulta, en gran parte, decepcionante. Tantas esperanzas puestas en la educación décadas atrás han terminado por disiparse y ahora estamos viendo el crecimiento de la frustración, la desorientación y hasta los resentimientos. Las causas son muchas. Este trabajo no es para incidir en ellas; sólo van a ser una referencia genérica, pues lo que nos interesa es reconsiderar la educación, tratar de reencantarla (De la Torre y Moraes, 2005).

Respecto a las causas, unas son de fuera del sistema educativo (políticas educativas poco afortunadas; instrumentación partidista de la educación; contradicción entre muchos valores que la sociedad pide que se practiquen en la escuela pero que la propia sociedad no practica...) y otras son endógenas (reducción del aprendizaje a lo cognitivo; resistencia al cambio, a los procesos de innovación; aprendizaje de contenidos desligados de sus contextos naturales y sociales, lo que le resta sentido al aprendizaje; metodologías poco innovadoras; insuficiente formación del profesorado, sobre todo el de secundaria; escuelas desligadas de su entorno comunitario, creciente nivel de conflicto que acaba en distintos tipos de violencia; profesores y alumnos desmotivados e incluso "quemados"...). Podemos decir que existe un malestar profundo en la educación. Debemos cuestionarnos qué debemos cambiar y cómo para superar este panorama. Desde hace tiempo se observa una enorme distancia entre los propósitos y los efectos del ejercicio de la práctica educativa, tal como desde los 70 y con distintas perspectivas acreditan Ivan Illich, A. S. Neill o Paulo Freire. Para Illich la educación entra en crisis como consecuencia de la problemática derivada de su implantación institucional; para Neill será la coacción en forma de directividad ejercida por padres y maestros la que distancie a los sujetos de los objetivos de la educación, mientras que para Freire será la educación bancaria, ejercicio de aprendizajes alienantes los que impidan el éxito en la tarea educativa.

La crisis de la educación no es una novedad, por ello nos preguntamos sobre la causalidad de la brecha descrita y apuntamos a que, por un lado, el significado mayoritariamente compartido por los responsables y actores de la educación se reduce más a fenómenos como la socialización, instrucción o transmisiónadquisición de cultura olvidando otros aspectos que imposibilitan hablar de educación en su pleno sentido. Por otro, el sistema educativo vive de espaldas a la comunidad, tal como señala Hargreaves $(1998,2003)$ y sobre todo no promueve una personalidad integrada como señala Faure (1973) cuando habla de tender "hacia el hombre completo" y sostiene que

para las necesidades de la instrucción se ha destacado arbitrariamente una dimensión del hombre, la dimensión intelectual bajo el aspecto cognoscitivo, y se han olvidado o descuidado las otras dimensiones que se encuentran reducidas a su 
estado embrionario o se desarrollan de manera caótica. So pretexto de las necesidades de la investigación científica o de la especialización, se ha mutilado la formación completa y general de numerosos jóvenes (Faure, 1973, 234-235).

Diversos autores (Hargreaves, Fullán, Claudio Naranjo, Goleman, Gardner...) han insistido en lo mismo: el nulo carácter integral de la educación. Así, p. ej., Hargreaves $(1998,2003)$ habla de la necesidad de "profundización" del cambio educativo: la educación se ha centrado en lo cognitivo olvidando las otras "inteligencias" (social, emocional de Goleman, moral, la de los estados del yo de Loevinger, las "inteligencias múltiples" de Gardner, como la viso espacial, la musical, la corporal cinestésica...). Unido a esto también señala otro parámetro relacionado con el anterior: la "ampliación" (Hargreaves, 1998, 2003): es decir, la necesidad de abrir las escuelas a la comunidad, trayendo también esta a la escuela para que luche a su lado, si lo que se pretende es lograr mejoras significativas. Las escuelas no pueden seguir siendo centros aislados dentro de sus comunidades.

La consecuencia de esta visión reducida de la educación repercute en la experiencia cotidiana: "En las escuelas hay más "cabezas" que corazón, mucha "más mente" que cuerpo, mucha más "ciencia" que arte; mucho más "trabajo" que "vida", muchos más ejercicios que "experiencias" [...] mucha más "pesadumbre y aburrimiento" que "alegría y entusiasmo", (Toro, 2005, 21). Por ello, consideramos necesaria una labor de reelaboración de la noción de educación que vaya más allá de la acción de construcción personal centrada en lo "cognitivo" orientada a la adaptación económica en cuanto vía de éxito social.

\section{CAMBiar la educación, Pero ¿̨CON Qué DiRectriz?}

Distintos autores (Botkin y otros, 1979) sugieren que el sistema educativo de los países más desarrollados necesita importantes modificaciones con el fin de evitar que éste caiga en una crisis de mayor calado. Al igual que otros sectores estratégicos de nuestro sistema social han ido transformando sus estructuras, adaptándose a las nuevas exigencias socioeconómicas, el sistema educativo necesita también replantear sus fines, sus contenidos, sus formas de transferir y desarrollar la cultura, sus procedimientos de gestión y organización.

Existe un amplio consenso entre los expertos sobre la necesidad de cambiar el sistema escolar actual para adaptarse a la sociedad del siglo XXI, el problema surge cuando nos planteamos: cambiar la educación y la enseñanza, pero ¿en qué dirección?, ¿con qué fines? ¿Al servicio de qué modelo social, económico, político? En la contestación a estas cuestiones surgen las divergencias y se hacen explícitos los planteamientos pedagógicos e ideológicos de quienes observan la institución escolar y construyen las respuestas.

Sabido es que la institución escolar, tal como la conocemos, es un invento del siglo XIX para dar respuesta a las nuevas necesidades de las emergentes sociedades industriales europeas y del mismo modo que las ciudades se adaptaron al modo 
de producción fabril, la actividad educativa también pasó de lo artesanal a lo industrializado. La aparición de los Estados nacionales, junto con la necesidad de una mano de obra alfabetizada hizo necesario articular un sistema de formación de masas gestionado por las autoridades públicas. Este sistema educativo sirvió para tres metas fundamentales: transmitir una cultura nacional común a las generaciones jóvenes, formar las actitudes de los nuevos obreros y alfabetizarlos para que supieran leer y escribir.

El modelo elegido para esta producción de sujetos instruidos se basó en dos acciones principales, una, la transmisión de la "cultura" fragmentada y graduada en textos que señalaban qué aprender-enseñar a maestros, que se encargaban de atender a un grupo de alumnos durante un periodo temporal definido -el curso escolar- y otra, en la creación de espacios específicos para la actividad educativa -escuelas y aulas-. Durante los siglos XIX y XX éste ha sido el modelo de escolarización a gran escala que mayor grado de implantación ha tenido en todos los países (Álvarez Uría y Varela, 1990).

En la actualidad, la sociedad se rige por parámetros que llevan a definirla como del "conocimiento" o de la "información". La noción "sociedad de la información" se utiliza sobre todo cuando se tratan aspectos tecnológicos y sus efectos sobre el crecimiento económico y el empleo. Esta visión tiene como punto de partida la consideración de que la producción, la reproducción y la distribución de la información son el principio constitutivo de las sociedades actuales. Pero, tanto en el ámbito de las ciencias sociales como en el ámbito político, se observa que este término es reemplazado por el de "sociedad del conocimiento" lo que implica un cambio conceptual de la "información" al "Conocimiento" considerándolo como principio estructurador de la sociedad actual, resaltando su importancia en los cambios del sistema económico, de los mercados laborales, la educación y la formación (Heidenreich, 2003). Otra noción de uso común en el campo de las ciencias sociales es "sociedad red" (Castells, 1996). Se trata de un concepto que está situado entre la "sociedad de la información" y la "sociedad del conocimiento". Castells señala diferencias y distingue entre "información" e "informacional". Información es comunicación del conocimiento, mientras que informacional indica la propiedad de una forma específica de organización social, en la que la generación, el procesamiento y la transmisión de la información se convierten en las fuentes fundamentales de la productividad y el poder, debido a las nuevas condiciones tecnológicas que surgen en este periodo histórico.

Al igual que el concepto "sociedad del conocimiento", el de "sociedad red" plantea que la transformación actual de la sociedad muestra un cambio de modo de producción social. Dada la creciente importancia de la información, o del conocimiento, para los procesos socioeconómicos, información y conocimiento se convierten en los factores productivos más importantes. Sin embargo, Castells (1996) declara que ni la tecnología determina la sociedad, ni la sociedad dicta el curso del cambio tecnológico, el enfoque de la sociedad red parte de la idea de 
una tecnología ya asumida e investiga los efectos de la aplicación de los inventos tecnológicos sobre la sociedad. La imagen de red se debe a que la tecnología es una construcción social en cuyo desarrollo intervienen múltiples actores, diferentes intereses conformando un entramado de interacciones.

Como vemos la "educación" aparece como condición necesaria para el avance socioeconómico pero ya no será de carácter masivo destinada a formar los aspectos personales de los obreros industriales, ahora requiere de una formación adaptada a ámbitos de pequeña escala, en los que se gestiona información y conocimiento. Esta nueva sociedad de la información necesita que se den tres condiciones básicas: A) Tecnología de la comunicación más avanzada que la actual. B) Una importante inversión económica para crear un entramado de economía digital configurando lo que se conoce como nueva economía y C) Un importante contingente de ciudadanos con suficiente grado de formación que les permita consumir los productos que ofrecen las tecnologías de la comunicación y ser trabajadores de las mismas.

Sin embargo, este tipo de sociedad hacia la que caminamos seguirá siendo una sociedad injusta, asentada en una distribución desigual de la riqueza, donde el poder adoptará nuevas formas de control, se seguirá degradando la vida sobre el planeta y los ciudadanos alienados de su potencial de desarrollo personal, en función de las nuevas exigencias del sistema productivo. En consecuencia, nos encontramos ante una perspectiva economicista, ante un fenómeno que ya ocurrió anteriormente con la primera y segunda revolución industrial, por lo que consideramos necesario poner en valor el discurso pedagógico que entiende que la educación es un instrumento para la emancipación y desarrollo (crecimiento) humano y no sólo formación para la inserción laboral. Y esto es especialmente remarcable en la actualidad debido a que la cultura y la tecnología digital están generando un nuevo tipo de analfabetismo entre la población adulta occidental. Incluso se llega a cuestionar el modelo clásico de escolaridad en el sentido de que para modernizar la enseñanza se reclama que ésta debe abrir sus puertas a las Tecnologías de la Información y Comunicación (TIC) y reconfigurar en su totalidad su concepción, de tal manera que los centros actuales sean sustituidos por medios cibernéticos. Por otra parte, hay quienes postulan por una perspectiva humanista de tradición ilustrada. Para ellos, la escuela actual debe cambiar recuperando los valores de la cultura humanista, liberal, adaptada, eso sí, a un mundo dominado por la ciencia y la tecnología. Es en este panorama donde queremos hacer nuestra aportación acerca del sentido de la acción educativa, de su alcance, de su profundidad.

Nos planteamos la educación como proceso de antropogénesis, no sólo en el ámbito del desarrollo personal, sino también de las dimensiones transpersonales del ser humano, expresión que se explicará más adelante. Una visón completa de la propuesta se muestra en el Cuadro 1, con las tres grandes concepciones acerca de la educación. Las dos primeras concepciones de lo educativo son conocidas, la tercera está naciendo. 


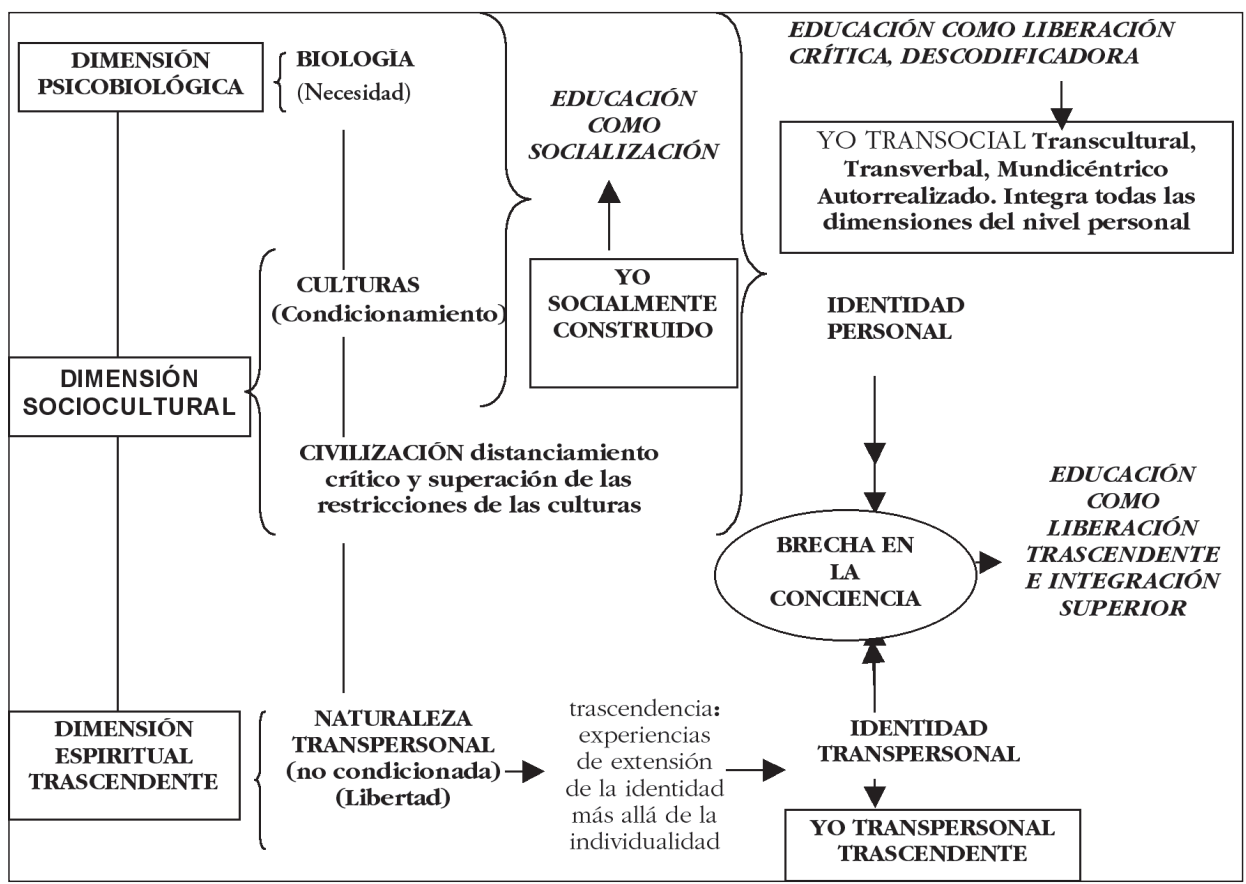

Fuente: Elaboración propia.

2. LA EDUCACIÓN COMO SOCIALIZACIÓN: PRIMERA GRAN ETAPA DE LA EDUCACIÓN COMO PROCESO DE ANTROPOGÉNESIS

Se van a presentar distintas lecturas o enfoques (antropológico-educativa, psicológico-educativa) en los diferentes apartados. Estas perspectivas enriquecen el tema estudiado: el despliegue del desarrollo humano, su lucha por ir dando a luz la humanidad que lleva y construye. Es el relato de un aprendizaje inmensamente rico, pero que se hace más rico y sorprendente conforme su desarrollo alcanza cotas cada vez mayores. Este proceso de antropogénesis es, pues, un proceso educativo.

\subsection{Lectura antropológico-educativa}

Nacemos como individuos de la especie humana, pero carecemos de conducta humana. Si el paso de ser individuo de la especie humana a tener conducta humana tiene que ser aprendido, ya que no es un proceso instintivo, quiere decir que 
el proceso de hacerse del hombre (antropogénesis) es un proceso educativo, pues el aprendizaje es el corazón de la educación y no hay nada más radicalmente educativo que el aprendizaje de lo humano. El aprendizaje y, por consiguiente, la educación alcanzan, desde esta perspectiva, su verdadero y hondo calado antropológico, ya que por el aprendizaje nos construimos como seres humanos al incorporar la herencia cultural de un grupo humano. La educación se constituye así en una forzosidad de la condición humana. El hombre tiene, pues, que aprender a ser humano. No nacemos hombre, nos hacemos. La cultura con sus moldes/patrones de conocimientos, creencias, actitudes, conductas se transmite a través de las instituciones sociales conformando el sistema nervioso y endocrino del individuo, por procesos de socialización y, por tanto, de aprendizaje, constituyéndose patrones muy complejos que se asumen de forma relativamente diferenciada por personas y grupos, pero el mecanismo es invariablemente el mismo: la asimilación como internalización de valores, actitudes, habilidades, creencias, normas, conductas y estilos de vida que constituyen lo adquirido. De esta forma aparece el primer nivel de conflicto, el más básico, como consecuencia del choque entre ese yo presocial, egocéntrico, impulsivo, movido por la espontaneidad y la agresividad de las exigencias pulsionales y la progresiva adquisicición de la cultura. El ámbito de la necesidad, el de la biología, tiene que ser "trabajado" por los condicionamientos sociales, de esta forma la socialización es una conquista de la herencia cultural, es código genético modelado por la cultura, es aprendizaje por el que un individuo de la especie humana pasa a tener conducta humana, y en ello está presente la autocoacción, el autocontrol o la doma de la espontaneidad instintiva de las zonas más antiguas del cortex cerebral por otras más evolucionadas, modernas. Si este conflicto no se supera positivamente no podemos hablar del paso del animal humano (individuo de la especie humana pero sin conducta humana) al animal cultural, es decir, con conducta humana (Fullat, 1978, 1992; Escámez, 1989). En esencia, consiste en la transmisión de manera inconsciente y no formalizada, al principio de la vida, de los conocimientos, valores, hábitos, actitudes y creencias que constituyen el entramado básico de una sociedad. Enseguida la escuela se constituye en una de las instituciones privilegiadas de esta socialización. Es una acción que va de «lo social" a "lo individual" conformando progresivamente una subjetividad. Muchas de las conductas antisociales, especialmente en los jóvenes, pueden explicarse por fallos en la realización de estos procesos de socialización primaria. Cuando se realiza positivamente podemos hablar de educación como socialización que produce ese ensamblaje social, el paso de un yo presocial, preconvencional, a un yo social, convencional (Kohlberg), con-formista (Loevinger) y etnocéntrico (Wilber). La socialización, pues, dota al ser humano de las bases de su personalidad y el fundamento necesario para vivir en sociedad. Las claves psicológicas generales de este proceso se ven a continuación. 


\subsection{Lectura psicológico-educativa}

El desarrollo de las sucesivas lecturas psicológicas sólo será muy sintético e incompleto pues no podrá extenderse en la explicación de las distintas líneas de desarrollo o líneas educativas, ni siquiera las que aparecen en los cuadros. Pero consideramos que lo que aquí importa es la idea que se transmite: la enorme riqueza de lo que de hecho es la educación y el aprendizaje como contraste de lo que acaba siendo en la práctica. La psicología evolutiva ha descrito este nivel desde diferentes líneas de desarrollo: moral, cognitiva, emergencia del yo, necesidades básicas, etc. (cfr. Wilber, 1997, 189-318; 1991, 109-128 y 257-263; 1989, 22-131; 2000, 322-342; 1988, 39-58; 2005, 199-377) (ver Cuadro 2).

Cuadro 2. Desarrollo EVOlutivo CORRESPONDIENTE a la EDUCACión COMO SOCIALIZACiÓN

\begin{tabular}{|c|c|c|c|c|c|c|}
\hline $\begin{array}{c}\text { Niveles de } \\
\text { emergencia } \\
\text { del Yo } \\
\text { WILBER }\end{array}$ & Descripción & $\begin{array}{c}\text { Niveles de } \\
\text { Identidad } \\
\text { WILBER }\end{array}$ & $\begin{array}{c}\text { Estructuras } \\
\text { Básicas } \\
\text { PIAGET }\end{array}$ & $\begin{array}{c}\text { Necesidades } \\
\text { MASLOW }\end{array}$ & $\begin{array}{c}\text { Estados del } \\
\text { Yo } \\
\text { LOEVINGER }\end{array}$ & $\begin{array}{c}\text { Juicio } \\
\text { Moral } \\
\text { KOHLBERG }\end{array}$ \\
\hline $\begin{array}{c}\text { YO FÍSICO } \\
\text { (primeros } \\
\text { meses) }\end{array}$ & $\begin{array}{l}\text { Uno con el } \\
\text { mundo }\end{array}$ & Fisiocéntrica & $\begin{array}{c}\text { Conoc. } \\
\text { sensoriomotriz }\end{array}$ & Fisiológicas & $\begin{array}{c}\text { Presocial } \\
\text { autista }\end{array}$ & \\
\hline $\begin{array}{c}\text { YO } \\
\text { CORPORAL- } \\
\text { EMOCIONAL } \\
\text { (1-3 AÑOS) }\end{array}$ & $\begin{array}{l}\text { Uno con el } \\
\text { cuerpo }\end{array}$ & Biocéntrica & $\begin{array}{c}\text { 1. }{ }^{\circ} \text { imágenes- } \\
\text { emociones } \\
\text { ligadas al } \\
\text { cuerpo }\end{array}$ & $\begin{array}{l}\text { Seguridad } \\
\text { (inicios) }\end{array}$ & $\begin{array}{l}\text { Simbiótico } \\
\text { impulsivo }\end{array}$ & \\
\hline $\begin{array}{l}\text { 1. Mental } \\
\text { básico } \\
\text { (3-7 años) }\end{array}$ & $\begin{array}{c}\text { Funciones } \\
\text { intelectuales } \\
\text { básicas. } \\
\text { Lenguaje }\end{array}$ & $\begin{array}{c}\text { Noosférica } \\
1 . \\
\text { Egocéntrica }\end{array}$ & $\begin{array}{l}\text { Pensamiento } \\
\text { preoperacional }\end{array}$ & Seguridad & Autoprotector & $\begin{array}{c}\text { Pre- } \\
\text { Convencional } \\
\text { egoísta }\end{array}$ \\
\hline $\begin{array}{l}\text { YO MENTAL } \\
\text { 2. Mental } \\
\text { concreto } \\
\text { (7-12 años) }\end{array}$ & $\begin{array}{l}\text { Uno con la } \\
\text { corriente } \\
\text { psicomental }\end{array}$ & $\begin{array}{c}2 . \\
\text { Sociocéntrica } \\
\text { Etnocéntrica }\end{array}$ & $\begin{array}{c}\text { Operacional } \\
\text { concreto }\end{array}$ & $\begin{array}{l}\text { Pertenencia } \\
\text { Arraigo, Amor }\end{array}$ & Conformista & $\begin{array}{c}\text { Convencional } \\
\text { Centrado en } \\
\text { el grupo }\end{array}$ \\
\hline
\end{tabular}

Fuente: Adaptación de Wilber (2000).

El yo emerge alrededor de los cuatro meses en un proceso de diferenciación entre sus sensaciones físicas y el entorno; antes no existía yo, o, si se quiere, se podría describir como un estado de fusión con el mundo sensoriomotor, de narcisismo primario en el que su identidad es fisiocéntrica. Descrita por Piaget como "protoplasmática"; como "pleromática" y "urobórica" por Jane Loevinger. Una vez que atraviesa este nivel en el que el niño ha establecido las fronteras de su yo físico, el yo aparece como cuerpo, como ego corporal en el que desvía su atención 
desde el pleroma ${ }^{1}$ hasta su cuerpo. El niño se identifica con sus sensaciones y emociones que provienen de relacionarse con el mundo sólo desde su corporalidad, con lo que empieza a sentirse yo emocional. Al trascender su primitivo estado de fusión puede realizar operaciones físicas sobre el mundo utilizando como herramientas las estructuras propias de ese nivel, que en este estadio es el cuerpo sensoriomotor. Este estado es muy egocéntrico y narcisista, es decir, considera al mundo emocional y vital como una extensión de sí mismo, pues su yo no puede diferenciarse del mundo emocional; da por hecho que lo que él está sintiendo, lo que quiere o lo que ve es lo que el mundo está sintiendo, quiere o ve. Esto no es patológico en este momento. Su identidad es, pues, biocéntrica, ya que aún no se ha diferenciado del entorno emocional. Este ego corporal-emocional está dominado por lo instintivo e impulsivo, por el principio del placer y las descargas involuntarias... todos estos procesos primarios e ídicos (del id o ello) han sido muy bien descritos por Freud. Este nacimiento emocional del niño implica despertar al hecho de que es un yo separado, con toda la carga de gozo y terror. Ésta es la aparición del dualismo básico yo, no-yo; el nacimiento de la escisión sujeto-objeto, de la conciencia fragmentada.

El avance prosigue cuando el yo deja de estar exclusivamente identificado con el nivel emocional y empiezan a emerger del ego corporal-emocional funciones auténticamente mentales, penetrando en un mundo de símbolos, ideas y conceptos (estadio preoperacional de Piaget), lo que le va a empezar a permitir elevarse por encima de las fluctuaciones del instintivo, inmediato e impulsivo ego corporal, postergar y canalizar las exigencias de sus descargas biológicas, con lo que ya no estamos totalmente a merced de los apremios instintivos, comenzando a trascenderlos. Esto significa que el yo empieza a diferenciarse del cuerpo y comienza a emerger como un yo mental, verbal, sintáctico. Aquí empieza a aparecer un yo lingüístico. Esta etapa se corresponde con las necesidades de seguridad de Maslow, con un estado del yo: el autoprotector (Loevinger), con el pensamiento preoperacional (Piaget). Comienza a desarrollarse un sentido moral (preconvencional) especialmente al final de la etapa, que es cuando aparece lo que Piaget llama el pensamiento operacional concreto, que implica un nuevo salto, una profundización en el mundo mental, conceptual. Su yo pertenece a un nuevo mundo: al de la noosfera. El lenguaje, con su linealidad, estructura la conciencia con un antes y un después, lo que le da un sentido temporal lineal. El yo puede pensar ahora en el pasado, y planificar el futuro. El yo se hace temporal e histórico. Pero en el pasado puede haber dolor, remordimientos, culpa y anticipar el futuro puede implicar preocupación, tensión, ansiedad. Éste es el nuevo paisaje de este mundo mental al que ha accedido.

1. Pleroma significa el universo material visto como materia prima y virgo mater. Es un término gnóstico. El uroboros es el símbolo mitológico de la serpiente que se muerde la cola y hace referencia a la incapacidad de salir de sí mismo (autista y narcisista). 
Trascender el mundo anterior, el mundo biológico, implica utilizar las herramientas propias del mundo mental para operar sobre el mundo concreto y sobre su propio cuerpo lo que le va a permitir demorar las descargas corporales controlando su inmediatez y exigencias; puede postergar la gratificación instintiva mediante la palabra, el razonamiento; puede sublimar sus energías emocionales-sexuales hacia actividades más sutiles, complejas y evolucionadas.

Pero este proceso de trascendencia tiene sus peligros como bien expuso Freud, pues el mundo mental puede reprimir a la esfera de la vida y esto se llama neurosis, si hablamos a nivel individual y crisis ecológica si lo vemos desde la perspectiva colectiva. Cuando esto se hace ya sabemos que lo reprimido reaparece de forma encubierta y dolorosa: son los síntomas neuróticos. Éste es el primer estadio en el que puede darse esta represión. La terapia en este nivel (terapias de descubrimiento) consiste en relajar las barreras de la represión para restablecer contacto con ese mundo de los impulsos, emociones y sensaciones reprimidas por el yo neurótico, un mundo que el yo experimentaba como peligroso. La represión es una reacción exagerada de los mecanismos de defensa, que son como una especie de sistema inmunológico del psiquismo cuya función es mantener la estabilidad e integridad de las fronteras del yo, enfrentándose a los ataques amenazantes; pero la represión es una respuesta desproporcionada que hace que los mismos mecanismos de defensa acaben atacando al mismo yo (igual que los trastornos autoinmunes a nivel físico). Wilber $(1997,231)$ expresa la situación de forma muy intuitiva cuando afirma que "En tal caso, las fuerzas de seguridad se transforman en un estado policiaco en el que el yo se defiende del sufrimiento y del miedo encarcelando a sus propios ciudadanos".

La neurosis infantil es bastante fácil; ocurre cuando un niño ha sido suficientemente dañado a nivel emocional, por ejemplo, en la familia, para que pueda percibir las emociones y afectos con un nivel de miedo y amenaza, por el sufrimiento causado, que termine reprimiéndolos en el inconsciente. Esto significa que se niega a admitir parte de su potencial, divide su ser y trata de vivir a un lado de esa división, negando ese otro mundo que debería integrar: el emocional, afectivo. El yo oculta a sí mismo parte de lo que es. Es decir, se miente, cierra los ojos y se aleja de esas facetas que le resultan muy dolorosas y amenazantes. Y así medio vive, durante un tiempo, una vida llena de mentiras y si experimenta una crisis puede desplomarse o compartir sus verdades interiores en un ambiente amigable y acabar encontrándose con el verdadero yo que fue negado.

El siguiente paso se da durante la preadolescencia, cuando emergen del yo, identificado hasta ahora con el pensamiento preoperacional, otras capacidades. A nivel cognitivo, son las del pensamiento operacional concreto que implica la capacidad de aprender reglas mentales y de asumir roles mentales, y, lo que es muy importante, la capacidad de asumir el papel de los demás. Antes el niño no era capaz de ponerse en el rol de los demás, ahora sí, y éste es un paso importante en el camino hacia lo global, a asumir que su perspectiva no es la única perspectiva. Su actitud moral cambia, de una actitud egocéntrica y preconvencional a una 
convencional y muy conformista. En estos momentos el grupo familiar, social, de iguales... es muy importante, necesita sentirse pertenecer a ese grupo, su moral es la del grupo, su nivel de identidad es sociocéntrico, etnocéntrico. Asume los guiones, la visión, la moral... de la vida social del grupo. Su ensamblaje social se completa.

Es importante captar el sentido general del proceso de antropogénesis: «El proceso de desarrollo humano puede ser considerado como una continua disminución del egocentrismo" (Wilber, 1997, 245). El narcisismo o egocentrismo era total cuando el niño es incapaz de diferenciarse del mundo, pero al nacer como yo corporal deja de tratar al mundo físico como una prolongación de sí mismo. De forma análoga ocurre cuando nace como yo emocional, que deja de creer que todos participan de sus sentimientos, que lo que él siente lo está sintiendo todo el mundo. Con el nacimiento del yo conceptual, en su primera etapa: egocéntrica, todavía no puede asumir el papel de los demás, considerando que su perspectiva es universalmente comprendida y que personas, plantas y animales participan de su conciencia. Cuando su yo mental entra en la etapa sociocéntrica es cuando su descentramiento es aún mayor y su ego ha dejado de ser ya el centro del mundo. Pero aquí se queda en el grupo; es etnocéntrico; aún no puede descentrarse de su grupo. Éste tiene lo que es bueno, natural, correcto y, por supuesto, toda su consideración; ahí afuera está lo otro. Mi consideración y el respeto se han expandido desde mí hasta el grupo; es bastante, aunque no suficiente. Aquí el yo está perdido en el grupo, en sus guiones sociales.

Muchos de estos guiones son necesarios y cumplen su función en esta etapa, pero otros están distorsionados y son insanos, con lo que nos encontramos con la patología propia de este nivel. De nuevo el engaño ronda la construcción del yo. Aparece en expresiones tales como "soy una mala persona", "nunca puedo hacer bien las cosas", "si ella no me quiere nadie me querrá", "si fracaso en esto, significa que fracasaré en todo"... Estos falsos guiones son la forma que asume la mentira en este nivel y esas mentiras sociales son las que construyen el falso yo, perdiendo así el contacto con todos los roles positivos que podría asumir en el mundo social en el que está. La terapia consistirá en "hacer frente a las reglas, los guiones y los juegos falsos y distorsionados, guiones que no están basados en la evidencia presente, guiones irreales, mitos, en suma, que no resisten la evidencia racional, (Wilber, 1997, 248).

\section{TRANSICIÓN DE LA EDUCACIÓN COMO SOCIALIZACIÓN A LA EDUCACIÓN COMO LIBERACIÓN CRÍTICA}

Esta etapa evolutiva es de transición ya que el nivel mental abstracto empieza siendo socialización, y acaba estando más cerca de la educación como liberación crítica que de la educación socializante.

Sólo damos una lectura psicológica, en sus aspectos más específicos. La antropológica se da por vista con lo dicho en la fase anterior y con lo que se expondrá en la siguiente. 
Cuadro 3. Desarrollo evolutivo de la etapa de transición: DESDE LA EDUCACIÓN COMO SOCIALIZACIÓN A LA EDUCACIÓN COMO LIBERACIÓN CRÍTICA

\begin{tabular}{|c|c|c|c|c|c|c|}
\hline $\begin{array}{c}\text { Niveles de } \\
\text { emergencia } \\
\text { del YO } \\
\text { WILBER }\end{array}$ & Descripción & $\begin{array}{c}\text { Niveles de } \\
\text { identidad } \\
\text { WILBER }\end{array}$ & $\begin{array}{c}\text { Estructuras } \\
\text { básicas } \\
\text { PIAGET }\end{array}$ & $\begin{array}{c}\text { Necesidades } \\
\text { MASLOW }\end{array}$ & $\begin{array}{c}\text { Estados } \\
\text { del Yo } \\
\text { LOEVINGER }\end{array}$ & $\begin{array}{c}\text { Juicio } \\
\text { KOHLBERG }\end{array}$ \\
\hline $\begin{array}{c}3 . \text { Mental } \\
\text { abstracto } \\
(12 / 5-21 \\
\text { años })\end{array}$ & Autorreflexión & $\begin{array}{c}\text { Mundicéntrica } \\
\text { temprana }\end{array}$ & $\begin{array}{c}\text { Operacional } \\
\text { formal }\end{array}$ & Autoestima & $\begin{array}{c}\text { Conformista } \\
\text { consciente } \\
\text { individualista }\end{array}$ & $\begin{array}{c}\text { Ley y orden } \\
\text { Post- } \\
\text { convencional }\end{array}$ \\
\hline
\end{tabular}

Fuente: Adaptación de Wilber (2000).

\subsection{Lectura psicológico-educativa}

Es una transición que aparece, en nuestra cultura occidental, entre los 12 y los 15 años, con la emergencia de una nueva estructura en la conciencia del yo (identificada, hasta ahora, con la mente operacional concreta) que constituye el estadio de las operaciones formales. Aquí el pensamiento puede operar (pensar) sobre sí mismo, lo que posibilita una auténtica introspección. Esta capacidad es fundamental ya que nos permite enjuiciar los roles, las reglas y los guiones sociales del estadio anterior. Antes sólo podíamos asumirlo de forma irreflexiva. Y puesto que puedo enjuiciar y, por tanto, criticar a la sociedad convencional, puedo también cuestionar sus normas y estar en desacuerdo con ellas o de acuerdo con parte de ellas (Loevinger lo denomina conformismo consciente), lo que implica que se ha distanciado, que no está identificado con ellas y, en esa misma medida, las empieza a trascender, logrando así una cierta libertad que supone empezar a coger las riendas de su vida. Integrará esos roles y guiones sociales, pero no ya identificándose con ellos de forma exclusiva. Al empezar a cuestionar las visiones sociocéntricas y etnocéntricas, algo que antes no podía hacer, ha empezado a adentrarse en lo mundicéntrico, aunque aún de forma inmadura. Esto supone otra disminución del narcisismo, centrado ahora en su grupo, otro aprendizaje del descentramiento hacia otro nivel más universal. A nivel moral, quiere saber lo que es adecuado, no sólo para uno o para su grupo, sino para todo el mundo, con lo que se entra en el desarrollo postconvencional: ni mi ideología, ni mi cultura, ni mis conductas, ni mi dios, ni mi clan... son las únicas a tener en cuenta y a valorar. Se trata de una transformación difícil; ha sido un viaje muy largo con un camino lleno de falsas vías. Se trata de una transformación irreversible, pues cuando se contempla el mundo desde una perspectiva mundicéntrica, global, un mundo más allá del yo y de lo mío, de mi grupo, ya no se puede dejar de hacerlo. Esto se vive de forma madura en el siguiente nivel evolutivo (educativo). 
La patología propia de este nivel es la siguiente: afirmar que todos los individuos y movimientos son merecedores de la misma consideración y oportunidades (universalismo pluralista), en definitiva que todo el mundo es igual o que todas las culturas son igualmente dignas (no sólo en principio), debiendo tratar por igual a todos los grupos y personas, puesto que ninguna cultura o movimiento es mejor que los demás. Pero esto no es correcto porque no todas las posiciones ideológicas, políticas o todas las conductas o elementos culturales son igualmente dignos. Los nazis son etnocéntricos y su ideología no puede equipararse a una ideología mundicéntrica. Pero esta patología (se da en el multiculturalismo) se niega a reconocer diferencias de calidad entre las actitudes morales. De todo debe ser juzgado de manera equitativa se pasa a decir que nada debe ser juzgado y que las posiciones morales son equiparables, exceptuando la suya propia, que es mejor que todas las demás. Es una patología de la mente adolescente que cree haber superado el elitismo, pero que se ve obligada a mentirse a sí misma porque aún sigue atrapada en ese elitismo.

\subsection{Concepción educativa: educación como socialización}

Esta primera concepción de lo educativo es la más conocida y en la que mayormente se centra la práctica educativa habitual. Este nivel es fundamental, puesto que nos da el individuo humano con conducta humana; nos da ya un animal cultural, lo cual es la base para cualquier desarrollo posterior. Pero siendo esto muy valioso, la educación no puede agotarse en esta acción fundamentalmente reproductiva de la sociedad en los individuos. Algunos autores como Delval (1996) afirman que la educación consiste en el proceso histórico de institucionalización de un sistema de socialización cada vez más complejo en función del grado de desarrollo de una sociedad determinada. Vista así la educación se muestra como socialización especializada, al servicio de las exigencias del desarrollo socioeconómico del momento. El fin de la educación (según esta óptica), será proporcionar a los nuevos miembros de la sociedad los recursos intelectuales, culturales e instrumentales necesarios para su adaptación ${ }^{2}$ social. La instrucción aparece como un instrumento de la socialización escolar configurando una educación centrada básicamente en la enseñanza, con el fin de facilitar la adaptación al medio socioeconómico vigente, de tal manera que los cambios en la educación serán las acciones necesarias para mejor conformar a las personas a las exigencias del desarrollo tecnológico de cada época.

En toda esta etapa la educación ha funcionado fundamentalmente como factor de socialización, poniendo énfasis en conducir a una meta, que se ha señalado previamente. Educar es llevar al educando a la realización de un tipo ideal de persona, por lo que los métodos de dirección no pueden sino implicar algún tipo

2. Adaptación según Freire. 
de fuerza o coacción, por más que ésta se ejerza con "cariño" o de manera "Suave" por progenitores o maestros. El fin propuesto justifica como mal menor la acción impositiva. Sin embargo, en los dos últimos siglos, dos tendencias han polarizado el debate sobre la educación, la que admite cierto grado de imposición en un proceso normativo que, como tal, conlleva la sumisión a un deber ser externo al sujeto y la llamada durante los años 70 antiautoritaria, que elimina de raíz cualquier heteronomía a favor de la plena autonomía. Nuestra tesis es que en la actualidad aún no se ha implantado definitivamente esta segunda noción, entre otras cosas, porque requiere del triunfo de una comprensión de lo humano que se abre con la modernidad ilustrada, centrada en la libertad como fundamento, y que continúa abierta y en desarrollo aun siendo cuestionada por alguna vertiente de la postmodernidad. La libertad $^{3}$ se revela, de un lado, como noción clave que explica al ser humano, decisiva para entenderlo como sujeto moral y para dar cuenta de la convivencia sociopolítica y, del otro, el concepto mismo de libertad que cambia sustancialmente su contenido, pues de entenderse como libre albedrí ${ }^{4}$, pasa a concebirse como autonomía del sujeto. Esta doble conceptualización, ausencia de coacción y libertad, modifica sustancialmente la idea de educación por cuanto coloca en el fin de la misma el logro de la autonomía del sujeto en cuanto capacidad de autogobierno y ésta sólo se puede alcanzar desde la libertad.

\section{La EDUCACIÓN COMO LiberaCión CRítiCA, SEGUNDA GRAN ETAPA EN EL PROCESO DE ANTROPOGÉNESIS}

Cuadro 4. Desarrollo eVOlutivo CORRespondiente a la educación COMO liberación Crítica

\begin{tabular}{|c|c|c|c|c|c|c|}
\hline $\begin{array}{c}\text { Niveles de } \\
\text { emergencia } \\
\text { del YO } \\
\text { WILBER }\end{array}$ & Descripción & $\begin{array}{c}\text { Niveles de } \\
\text { identidad }\end{array}$ & $\begin{array}{c}\text { Estructuras } \\
\text { básicas } \\
\text { PIAGET }\end{array}$ & $\begin{array}{c}\text { Necesidades } \\
\text { MASLOW }\end{array}$ & $\begin{array}{c}\text { Estados } \\
\text { del Yo } \\
\text { LOEVINGER }\end{array}$ & $\begin{array}{c}\text { Juicio } \\
\text { KOHLBERG }\end{array}$ \\
\hline $\begin{array}{c}\text { YXISTENCIAL } \\
\text { Integración } \\
\text { cuerpo mente }\end{array}$ & $\begin{array}{c}\text { Transverbal } \\
\text { Transcultural } \\
\text { lo transpers. }\end{array}$ & $\begin{array}{c}\text { Mundicéntrica } \\
\text { madura }\end{array}$ & $\begin{array}{c}\text { Imaginación } \\
\text { intuitiva, } \\
\text { redes de } \\
\text { relaciones. } \\
\text { Holístico } \\
\text { integral }\end{array}$ & $\begin{array}{c}\text { Auto- } \\
\text { realización } \\
\text { Trascendencia }\end{array}$ & $\begin{array}{c}\text { Autónomo } \\
\text { integrado }\end{array}$ & $\begin{array}{c}\text { Principios dividuales } \\
\text { denciencia } \\
\text { Ética }\end{array}$ \\
\hline
\end{tabular}

Fuente: Adaptación de Wilber (2000).

3. La libertad explica la naturaleza humana y la razón es consecuencia de su despliegue.

4. Noción fundada en la idea de que la razón en cuanto facultad intrínsecamente humana permite la elección consciente entre el bien y el mal lo que nos hace responsables de nuestros actos. 
En el cuadro anterior se expone el desarrollo evolutivo correspondiente a la educación como liberación crítica o descodificadora. Sólo está compuesto por un nivel evolutivo. Empezaremos dando una lectura antropológica que en parte también correspondería al nivel anterior, a su etapa final, pero que vamos a colocar en este nivel, por ser aquí donde se cumple de forma madura. Después daremos la lectura psicológica.

\subsection{Lectura antropológico-educativa}

Si, como se ha dicho, el ser humano se define por la internalización de la herencia cultural, la existencia de muchas culturas nos indica las multiples formas de construirse este ser humano, pues cada cultura es una forma de manifestarse la naturaleza humana común, de concretarse en una identidad cultural y por ello mismo, en principio, toda cultura es igualmente digna. Pero el hombre, cuya estructura psicobiológica le exige ser cultural, no está, sin embargo, determinado por la cultura, sino que puede oponerse a ella, es decir, puede "trascenderla" proyectando nuevas creaciones culturales. Frente a los procesos de socialización puede oponer procesos de resistencia crítica, influyendo, penetrando, cambiando, en parte, moldes, actitudes, creencias, prácticas... de su cultura, lo cual es lo mismo que decir que el hombre puede reconducirse, transformarse a sí mismo, eligiendo, construyéndose de otra forma. Esto no sería posible si no hubiera un proceso de distanciamiento crítico respecto del propio molde cultural para poder así superar las restricciones de la propia cultura.

En este contexto aparece el segundo nivel de conflicto en el desarrollo humano, el que se refiere a la educación como liberación crítica, en parte decodificadora o desveladora de deficiencias de la propia cultura, y, en parte, constructora de nuevas respuestas. Ese mismo distanciamiento crítico es ya una desidentificación parcial respecto de la propia cultura y de su acción modeladora en uno mismo, lo que constituye un trascender el propio ensamblaje social, facilitando el paso progresivo de un yo convencional, con-formista (al ser con-formado por una cultura concreta), a un yo postconvencional, no etnocéntrico sino mundicéntrico (Wilber, 2000) lo que nos posibilita el diálogo con personas de otras culturas, no desde una mera aceptación de su existencia, sino del íntimo reconocimiento de que cada cultura es una concreción de parte de la enorme riqueza de la naturaleza humana común presente en todos los hombres; de que el otro realiza, en parte, algo que estando presente en su naturaleza, en la mía se ha quedado latente; de que el otro es un reflejo de lo que en parte yo no soy, de que me "habla" desde una humanidad que no puedo dejar de valorar como riqueza no explorada por mí.

Estamos planteando el encuentro de personas, de grupos, que superando restricciones de sus propias culturas, que deben dejarse atrás, sostienen y comparten aquellos impulsos universalizables que como verdaderos valores están presentes en toda cultura, es decir, aquellos aspectos de las culturas que pueden ser asumidos 
por otras, en cuanto que son concreciones valiosas de la común naturaleza humana y, como tal, dignos de ser incorporados a ese patrimonio común en construcción de valores culturales universalizables. Estamos hablando, pues, de cultura y de civilización diferenciándolos entre sí. Pérez Gómez (1998, 40), basándose en las aportaciones de Huntington, entiende «la cultura como una construcción singular, propia de un grupo humano situado en un contexto local y en una época concreta, independientemente de la magnitud de su influencia; mientras que por civilización se entiende la tendencia humana individual y colectiva a distanciarse y superar las restricciones de la propia cultura para integrarse o construir un horizonte más amplio y universal". Savater $(1997,161)$ sitúa en este segundo concepto, el de civilización, la labor de la educación y la posibilidad de universalización de los valores y entiende que "esa potencialidad que cada cultura posee de transmutarse en todas las demás, de no ser verdadera cultura sin transfusiones culturales de las demás y sin traducciones o adaptaciones culturales con las demás, es a lo que nos referimos al hablar de civilización y también de universalidad". Obviamente no se trata de homogeneizar culturalmente, sino de romper la percepción que nos lleva a pensar que hay culturas que permanecen inalterables, cuando la realidad apunta a que todas están sometidas, en mayor o menor medida, a transformaciones continuas, fruto del influjo civilizador de las demás.

Este nuevo escenario hace posible la resolución de los conflictos y problemas que se presenten derivados de la diversidad e indefinición de los valores culturales a través del diálogo y de una base común (podemos poner como ejemplo los derechos humanos o la Carta de la Tierra), la cual está integrada, para Camps (1994), por los valores morales universalmente consensuables, valores que emergen de la convivencia intercultural, del diálogo y que sirven de marco a las exigencias individuales y grupales y que son producto de la civilización (no sólo occidental) y a los que no se puede renunciar sin incurrir en concesión a la barbarie (Savater, 1997), sin desandar lo andado en el camino civilizatorio. Pérez Tapias (1996, 214), comentando el humanismo ecuménico de A. Schaff, dice que se trata de trazar un

camino intersubjetivamente viable para todos, transitable interculturalmente, para afianzar en último término el humanismo necesario, transculturalmente válido, "ecuménicamente" gestado desde las diversas tradiciones que nutren el proceso civilizatorio de la humanidad.

De esta forma, "Si cada cultura es potencialmente todas las culturas, las diferencias culturales pierden su inefabilidad y se convierten en manifestaciones concretas y mudables de una naturaleza humana común" (Savater, 1997, 161). De ahí que la civilización y, por consiguiente, la universalidad, no son un patrimonio exclusivo de ninguna cultura, sino un impulso de todas, como termina diciendo Savater. Los citados derechos humanos, puestos como ejemplo, con su carácter universal, son precisamente por ello un logro civilizatorio muy importante, y como tal logro son un patrimonio de la humanidad, pues a diferencia de las culturas, los logros civilizatorios pertenecen a todos. Los procesos civilizatorios son, pues, 
procesos de mestizaje. Este universalismo no se plantea contra las diferencias, pues ha sido asumido desde el diálogo por la comunidad internacional. Sin embargo, la homogeneización cultural como proceso de imposición etnocéntrica promovida de forma hegemónica por Occidente provoca respuestas a la defensiva, a menudo conflictivas y violentas, por parte de las culturas que se sienten amenazadas. ¿Qué ocurre entonces si nos encontramos con choques de esos derechos con ciertas tradiciones, costumbres o valores? Lo primero, admitir que no toda diferencia cultural, por el mero hecho de serla, es valiosa. Habrá que analizarla y compararla para descubrir si va en contra o no de los derechos humanos, pues el carácter universalista y por tanto civilizador de esos derechos obliga a las culturas a humanizarse. Es en la perspectiva de este humanismo transcultural asentado en el respeto de los derechos humanos fundamentales practicando, desde ellos, una política del reconocimiento (Taylor, 1993, 60 y ss.) de las diferencias culturales, pero ajustadas a la dignidad de los individuos, como la tensión entre universalidad y particularidad pueden resolverse. Salvando lo que afecta a la dignidad de las personas, que es lo básico de los referidos derechos, todo lo demás es campo abierto para la libre expresión de las diferencias. Los derechos humanos, con su universalidad transcultural, serían el patrón negativo que dice lo que no se puede hacer con las personas, pero queda abierta toda la riqueza de la enorme variedad de lo que se puede hacer.

La humanidad que cada individuo lleva, esa naturaleza común, es la raíz de todos los valores. Por eso el individuo concreto en su humanidad, o la persona humana concreta, es el valor supremo, es siempre fin y nunca está en razón de medio, reducido a objeto o cosa. La humanidad de la que cada hombre es portador y el respeto a su dignidad es el núcleo de dicho bumanismo transcultural, el cual demanda políticamente una ciudadanía compartida, cosmopolita, planetaria. Como sostiene Savater (1997, 160-161):

Sólo volviendo a la raíz común que nos emparienta podremos los hombres ser huéspedes los unos para los otros, cómplices de necesidades que conocemos bien y no extraños encerrados en la fortaleza inasequible de nuestra peculiaridad. Nuestra humanidad común es necesaria para caracterizar lo verdaderamente único e irrepetible de nuestra condición, mientras que nuestra diversidad cultural es accidental.

Dado que las culturas mantienen todo tipo de intercambios y de préstamos culturales,

es precisamente este mestizaje a partir del multiculturalismo [...] la vía hacia el cosmopolitismo que impulsa y reclama una civilización ya planetaria. El cosmopolitismo, arraigado como actitud en la personalidad de los individuos, abre a éstos, desde su singularidad, a la universalidad humana, a la vez que a través de ellos potencia la ósmosis entre las culturas particularizadas (Pérez Tapias, 1996, 203).

La construcción de esos valores comunes fundamentales como patrimonio de la humanidad, que se asientan en esa naturaleza humana común que nos emparienta, 
nos posibilita esa identidad mundicéntrica, intercultural, postconvencional, ese humanismo transcultural que busca concretarse en ciudadanía planetaria.

\subsection{Lectura psicológico-educativa}

Llegamos aquí al último gran estadio ortodoxo trabajado por la investigación convencional. La psicología occidental (Bruner, Flavell, Arieti, Koplowitz...) ya había señalado la existencia de estructuras cognitivas superiores y más elevadas que el pensamiento operacional formal. H. Koplowitz postula un estadio, por encima del cuarto de Piaget (operaciones formales), que llama "pensamiento sistémico". Bruner cree que se puede pasar de ser inteligentes (pensamiento formal) a ser inteligentes acerca de la inteligencia. Este nivel ha sido llamado "dialéctico", "integrador", "sintético-creativo"... Wilber lo llama "visión lógica" o panorámica, conciencia "lógico-imaginativa". "Si bien la mente formal establece relaciones superiores y creativas, la mente lógico-imaginativa establece redes de relaciones. Esta estructura puede ubicar una proposición entre muchas otras y ver de qué modo su verdad o falsedad afecta a la [...] de las demás. [...] Esta estructura constituye, pues, la primera que puede sintetizar, establecer conexiones, relacionar verdades, coordinar ideas e integrar conceptos" (Wilber, 1991, 262) lo que supone el inicio de una capacidad verdaderamente superior de sintetizar y de establecer redes complejas de conceptos. Esta estructura coincide, cuando es madura, "con lo que Aurobindo (místico indio), denominaba "mente superior" [...] capacidad de ver la verdad de un solo vistazo [...], la estructura más integradora del dominio personal, más allá de lo cual se halla el dominio de lo transpersonal" (Wilber, 1994, 202-203). Al hablar de visión e imaginación en esta estructura cognitiva no se está haciendo referencia a la fantasía inferior preverbal del ego corporal infantil, sino a la fantasía superior transversal como expresión del ser total del centauro. Es un modo de contactar realidades transverbales. "Debido a la intensa conciencia panorámica ofrecida en [...] su estado más maduro y altamente desarrollado, el individuo podría empezar a experimentar una profunda intuición e incluso iluminación que parece ir más allá del pensamiento y constituir una visión noética, numinosa, inspiradora, a menudo enestática y en ocasiones extática" (Wilber, 1988, 52). Esto le puede llevar a tener experiencias cumbres de fusión del yo con la naturaleza, lo que no debe confundirse con las experiencias místicas teístas. Frente a la tendencia del pensamiento formal a moverse con una lógica aristotélica dicotómica, la visiónlógica unifica a las partes y ve redes de relaciones. Este tipo de pensamiento implica una integración bihemisférica funcional de las capacidades de ambos hemisferios cerebrales: las lingüísticas del hemisferio izquierdo (si hablamos de una persona diestra, el hemisferio izquierdo es analítico, lógico, temporal, deductivo, lineal, matemático... procesa la información paso a paso, de manera secuencial, de ahí que sea la sede del lenguaje), y las no verbales del hemisferio derecho (mundo de la imagen, intuitivo, sintético creativo, artístico, expresividad corporal, espacial... procesa la información de manera holística). 
Su estructura cognitiva (visión-lógica, intuición, dialéctica) y su identidad (mundicéntrica) le permite asentarse en un perspectivismo postconvencional y universal. La visión-lógica es aperspectivista en el sentido de que dispone de una multiplicidad de puntos de vista y no privilegia automáticamente ninguno de ellos sobre los demás. Esto estaba ya implícito en su mundicentrismo. El tener en cuenta todas las perspectivas (hasta este momento del desarrollo no lo podía hacer de forma madura) puede llegar a ser desconcertante porque aparece la relatividad de todas las perspectivas y, por tanto, la sensación de no tener un fundamento. Existe el peligro de caer en el autocontradictorio "todo es relativo", o todo es igualmente válido, pero sólo es una posibilidad, pues el asumir la relatividad de los diferentes puntos de vista no significa que unas perspectivas no sean relativamente mejores que otras. Así, la visión mundicéntrica es mejor que la etnocéntrica y ésta mejor que la egocéntrica. Este aperspectivismo es un paso más en el proceso de descentramiento, de trascendencia, en que consiste en último término la educación como proceso de humanización. Esta estructura cognitiva al ser integral-aperspectival, frente a la racional, del nivel anterior, que sí asume una perspectiva "puede mantener en mente contradicciones, puede unificar opuestos, es dialéctica y no lineal, y unifica lo que de otra forma serían nociones incompatibles, siempre y cuando se relacionen en un nuevo holón superior, negadas en su parcialidad pero preservadas en sus contribuciones positivas" (Wilber, 2005, 233). La postmodernidad, en sus mejores aspectos, es una manifestación de este aperspectivismo en el mundo de hoy. Esto ha llevado mucha confusión en la conciencia colectiva cayendo, a menudo en la traducción popular de la afirmación postestructuralista (postmoderna) de que no hay perspectiva última, de que todo vale igual.

Es precisamente esta capacidad integradora de esta estructura cognitiva la que sirve de soporte para un nuevo salto del yo hacia este nivel, el de un yo integral. "Este es el motivo por el cual denomino centauro al yo propio de este estadio, un estadio en el que tiene lugar una integración entre la mente y el cuerpo, entre la noosfera y la biosfera, que configura un yo relativamente autónomo, un yo que ha superado el aislamiento [...], el egocentrismo, un yo integrado en redes de responsabilidad y servicio" (Wilber, 1997, 258). Este "centauro" ya maduro es una persona que define su identidad como una integración de mente y cuerpo: el organismo total. En él tiene que estar integrada también la sombra. Es corriente utilizar los términos de Jung: "Sombra" y "persona" para referirse al proceso dinámico de la represión. La sombra es el inconsciente personal; ya vimos más arriba que él estaba constituido por material que resultaba amenazante para el ego. La "Sombra" es lo que hemos reprimido, negado, enajenado. "Negar la existencia de este material no lo elimina porque, en tal caso, regresa en forma de obsesiones, miedos y ansiedades y dolorosos síntomas neuróticos. Por eso, si queremos eliminar los síntomas dolorosos y hacernos una imagen más exacta y sana de nosotros mismos, necesitamos desenterrar ese material, familiarizarnos con él y acabar reapropiándonos de él» (Wilber, 2008, 130). Si uno no trabaja con su "Sombra" para enfrentarse a ella, hablar con ella y, finalmente, convertirse en 
ella, pues, en definitiva, somos ella, nos saboteará mucho el trabajo de desarrollo personal y, por tanto, de la educación en otros campos. Hay muchas formas eficaces de terapia con la sombra. Destacamos la terapia de Gestalt y la terapia Cognitiva.

Wilber, citando un estudio de J. Broughton sobre estas personas, dice que «tanto la mente como el cuerpo son experiencias de un yo integrado" (Wilber, 1989, 82). Es decir, que el yo de este estadio es consciente tanto de la mente como del cuerpo como experiencias. Esto significa que el yo al tener esta conciencia es un yo que observa el acontecer de su mente-cuerpo y en tanto en cuanto lo hace, como lo observado no es el observador, está comenzando a trascender la mente y el cuerpo, al poder ser conscientes de ambos como objetos de conciencia, al poder observarlos. «En otras palabras, algo parecido a un Yo puramente observante, un testigo trascendental [...], está comenzando a diferenciarse claramente del yo empírico o yo objetivo; este es otro territorio, un nuevo ir hacia dentro que va más allá, un nuevo emerger que trasciende pero que incluye al ego empírico. A esta primera trascendencia del ego le estamos llamando centauro" (Wilber, 2005, 319-320). Precisamente esta capacidad de trascendencia permite poder integrar la mente y el cuerpo.

El "centauro" es transverbal, pues ha trascendido el ego verbal, pero no es aún transpersonal, pues sólo comienza a intuir realidades transpersonales. Además de suponer una integración de orden superior (es el cierre y, por tanto, la cumbre del desarrollo a nivel personal) es una importante transición hacia la vivencia, la experiencia de los reinos transpersonales. "Este centauro maduro [...] es el punto en el que, a mi entender, energías superiores comienzan a inundar el organismo, transfigurándolo incluso fisiológicamente" (Wilber, 1989, 104). Esto se puede mostrar, por ejemplo, en que dispone de más energía de la propia de su edad y/o que aparenta menos edad de la que tiene.

Hasta llegar al nivel de las operaciones formales, la aparición de las sucesivas estructuras básicas de la conciencia (esencialmente estructuras cognitivas; son estables y permanentes) depende de la edad. Más allá, no hay evolución automática, depende de nosotros. De ahí que en el cuadro que comentamos (Cuadro 4), no aparezca por primera vez edad alguna porque el centauro maduro no es un estado que se consiga necesariamente. Así, el pensamiento lógico-imaginativo o dialéctico, apenas se alcanzará, si no es con un trabajo intelectual de cierta complejidad. Sin embargo, las otras líneas de desarrollo expuestas en los distintos cuadros (niveles de identidad, necesidades...) son relativamente independientes de la edad, lo que significa que aunque aparezca en el cuadro en la misma fila (comparación horizontal), no quiere decir que, necesariamente, una persona en el nivel estructural de la visión lógica, por ejemplo, tenga que estar en el estadio de autorrealización (Maslow) o tener una moral centrada en la ética universal (Kolhberg), que son los que corresponderían con dicho nivel estructural. Debe quedar claro que la posible falta de correspondencia se establece entre el desarrollo cognitivo, por un lado, y el resto de las otras líneas de desarrollo, por otro. Además esta posible falta de correspondencia, al estar relacionada con el ejercicio de la libertad de las personas, es más factible en las últimas filas del cuadro que en las primeras. 
El centauro, pues, se encuentra en una situación de transición al ser la última estructura que integra todas las del nivel personal y eso implica que las empieza a trascender. Corresponde (según lo dicho, debería corresponder, es decir, debería tener un desarrollo correspondiente) a la autorrealización de Maslow, y los últimos estadios estudiados por Loevinger (estado del yo: integrado) y Kohlberg (ética universal) y tiene ante sí los niveles transpersonales, de los cuales recibe ya alguna influencia difusa. "El desarrollo moral tiende a avanzar desde "mí" (egocéntrico) hasta "nosotros" (etnocéntrico) y "todos nosotros" (mundicéntrico), ilustrando asî perfectamente las distintas olas por las que atraviesa el despliegue de la conciencia" (Wilber, 2008, 25). Es un ser mundicéntrico maduro. Advierte claramente lo que nos une más allá de la enorme diversidad individual y personal y cuando se observa a sí mismo, no es una observación meramente individual, sino que aprende acerca de la humanidad común que nos une, al observar esos aspectos en los que los seres humanos somos semejantes. De este modo, no sólo se está conociendo a sí mismo, sino que, a través del él, está conociendo a los demás.

5. Transición de la educación como liberación crítica (CENTAuro maduro) al nivel TRANSPERSONAL

El centauro, por todo lo dicho, "Comienza a ser transconsensual, transocial, transcolectivo y transadaptado" (Wilber, 1989, 97). Existe una línea que separa al ego maduro, adaptado socialmente, del centauro. Es lo que Wilber llama "bandas biosociales" que representan el límite último, la barrera más sutil de la cognición social, de las formas convencionales, egoicas, institucionales y sociales en las que se ha movido hasta ahora. Y esto no debe confundirse con lo presocial, que también es asocial; pero la distancia evolutiva entre ambas vivencias es de todo un mundo. Este carácter transconsensual y transocial supone la desintegración progresiva de las estructuras perceptuales y cognitivas automáticas lo que permite una experiencia sensorial superior, un crecimiento de la intensidad y de la riqueza perceptiva. En este caso el desarrollo de la atención y de la percepción tiene el énfasis puesto en el objeto (percepción o atención alocéntrica. Los niños tienen una apertura alocéntrica al mundo que después se pierde en la mayoría de los adultos. Ésta es preverbal, muy diferente de la transverbal de la que aquí hablamos). Frente a ella, está la percepción o atención sociocéntrica, que supone una contemplación del mundo a través de etiquetas, categorías, conceptos de las bandas biosociales. Dado que el centauro es transocial y transverbal, su percepción es alocéntrica. Al venirse abajo las estructuras cognitivas automáticas a través de las cuales veía, es como si tuviera que aprender a ver y a sentir de nuevo, trascendiendo la categorización. Aprende a hacerlo cada vez más desde el silencio y, por consiguiente, a costa de la categorización abstracta. Es cada vez más un observador que no enjuicia, que no manipula lo observado. Trasciende así la percepción social, los esquemas culturales, las bandas biosociales. El centauro, como consecuencia de los grados de libertad que alcanza, de su unidad cuerpo, mente y sombra, de su percepción 
desinteresada, alocéntrica... goza de un nivel de espontaneidad, que no es presocial, como la del niño, sino que es transocial, que está más allá de los rígidos controles del ego, hacia etapas de control transegoico. Este concienciamiento sensorial, liberado del lastre de la esquematización egoica y cultural, viene a ser una especie de conciencia supersensorial abierta a lo transpersonal, por la que tenemos acceso, especialmente en el mundo natural, a emociones como el sobrecogimiento ante la belleza, el misterio, la armonía... presente en la naturaleza, emociones propias ya del siguiente nivel de avance de la conciencia.

Otra característica de esta etapa es su vivencia del tiempo. El centauro maduro vive cada vez más en el presente inmediato, pero a diferencia del niño preverbal que está limitado al presente, porque desconoce el mundo del tiempo lineal, el centauro reside en el presente pero sin estar atrapado en él, todo, el pasado y el futuro lo vive como hechos del presente. Su vivencia del tiempo es transecuencial, trascendiendo, pues, el tiempo lineal. Obsérvese la relación entre la conciencia identificada con el lenguaje y la vivencia del tiempo lineal. El lenguaje es lineal, y cómo la conciencia transverbal del centauro supone, correlativamente, una trascendencia del tiempo lineal. Vivir sólo desde el aquí y ahora es real. Éste es un lema básico de la terapia Gestalt, que busca desarrollar la capacidad de vivir intensamente en el presente, un objetivo impresionante desde el punto de vista educativo.

Finalmente, el yo centáurico es un yo existencial; así es como aparece en el Cuadro 4. La vida no es precisamente fácil para el yo existencial. El adjetivo "existencial" le viene por su relación con el existencialismo. Estos filósofos han llevado a cabo un análisis muy acertado, profundo e interesante del yo existencial, centáurico, de sus características, sus modos de existencia, su actitud en el mundo. Podríamos decir que el existencialismo es una filosofía hecha desde este nivel (el del centauro) y para este nivel, con tal acierto, que todo el movimiento del potencial humano, de la psicología humanística y de todas sus interesantes terapias, son impensables sin el existencialismo y la fenomenología 5 . Pero los existencialistas han investigado también como nadie, en algo fundamental, en

las mentiras y la mala fe que impiden el logro de esa autenticidad. Mentimos sobre
nuestra mortalidad y finitud creando símbolos de inmortalidad, vanos intentos de
vencer al tiempo y existir eternamente en algún cielo mítico, en algún proyecto
racional, en alguna obra de arte a través de los cuales expresamos nuestra incapa-
cidad de afrontar la muerte. Mentimos sobre la responsabilidad de nuestras propias
decisiones, prefiriendo considerarnos víctimas pasivas de alguna fuerza externa;
mentimos sobre la riqueza del presente, proyectándonos hacia el pasado en la

5. Remitimos al lector, por la imposibilidad de hacer aquí una referencia adecuada, a la interesante exposición de QuiTman (1989) (ver bibliografía) en donde se expone, de forma detallada y clara, el trasfondo filosófico de la psicología humanística, es decir, el existencialismo y la fenomenología, relacionándolos con los conceptos centrales de la psicología humanística y sus autores. 
culpa y hacia el futuro en la ansiedad; mentimos sobre nuestra responsabilidad ocultándonos en la mentalidad de rebaño, perdiéndonos en el otro, en el falso yo, elaborando engañosos proyectos para ocultarnos de la conmocionante verdad de la existencia (Wilber, 1997, 261).

También aquí nos encontramos con una patología de nivel, con su enfermedad, tratada en las obras, sobre todo, de los existencialistas ateos. Tiene que ver con los temas del absurdo de la existencia, de la inanidad de la vida humana, del ser humano como ser para la muerte, en autores como Sartre, Camus, Heidegger; del hastío como respuesta auténtica del ser existencial (Heidegger), de un temor que abarca la totalidad de mi ser-en-el-mundo. Del sinsentido de todo ante la muerte, de la imposibilidad de la razón de romper el muro que me dé respuestas sin caer en fáciles dioses y cielos, que es caer en la vida inauténtica. De la angustia del existente, de su derelicción absoluta (desamparo) y aerrojamiento (Heidegger) en el mundo. El hombre está ahí, así, sin razón alguna. Es lo que Sastre y Heidegger llaman su facticidad; ¿por qué el hombre se encuentra ahí, en el mundo?, no se sabe, es idiota; ¿por qué?, por nada. El existencialismo pone vivamente al hombre frente a su desdicha. Mientras para Jaspers el ser humano tiende hacia un más allá de la existencia, para Heidegger sólo existe el mundo del hombre. Del porvenir sólo nos llega su urgencia trágica: la llamada de la muerte. Del tiempo, el sentimiento de contingencia original que se concreta en un sentimiento de vacío. La angustia es el sentimiento dominante desde Pascal a Sartre. En Heidegger es el signo del sentimiento auténtico de la condición humana, pues no me miento con dioses o de otras formas para eliminar esa angustia, que no lo es de ningún objeto concreto, sino de la percepción desnuda y brutal de nuestro ser-en-el-mundo, de nuestro desamparo radical y de nuestra marcha hacia la muerte (Mounier, 1967). Como puede verse no hay muchos motivos para sonreír, al fin y al cabo, el yo existencial no está anclado ya en el dominio de lo personal, que ha comenzado a perder su sentido y a parecerle absurdo, pero tampoco se ha adentrado en los ámbitos transpersonales (trascendentes) de la existencia. Está en una tierra de nadie.

Esta superación de lo personal es una temática tratada por Maslow (1963), uno de los padres de la psicología humanística (Goble, 1977; Matson, 1984; Rogers, 1987). Maslow sostiene que el hombre está motivado en su acción por la satisfacción de sus necesidades. Esta concepción aparece claramente en los psicólogos humanistas, que han descartado la teoría freudiana de los instintos en favor de una concepción de necesidades básicas o de la concepción de una sola necesidad imperiosa de realizarse a sí mismo y de crecer (Rogers, 1974, 1987) afirma la existencia de una tendencia actualizante del individuo que lleva a la totalidad de la persona a su desarrollo integral; esta tendencia puede ser frustrada de muchas maneras. Estas necesidades básicas (Maslow) se ordenan con cierta jerarquía, desde las más elementales hasta las más elevadas. Según Maslow, las personas sanas han satisfecho razonablemente sus necesidades básicas: 
fisiológicas, de seguridad, entrega, amor, respeto y autoestimación, de tal modo que ahora se sienten motivadas primordialmente por tendencias conducentes a la autorrealización (definida como autorrealización creciente de las potencialidades, capacidades y talentos; como cumplimiento de la misión [...] destino, vocación; como conocimiento y aceptación más plenos de la naturaleza intrínseca propia y como tendencia constante hacia la unidad, integración o sinergia, dentro de los límites de la misma persona) $(1979,56)$.

Tiene que ser satisfecha en parte, al menos, la necesidad más básica, que aparece debajo, para que surjan nuevas tensiones, nuevas motivaciones, que piden también ser satisfechas. Pero ¿qué ocurre con ciertas personas cuando tienen suficientemente satisfechas estas necesidades? Existen personas "que tienen un sentimiento de pertenencia y arraigo, que tienen amigos, se sienten amados y merecedores de amor; que tienen una buena posición social, un lugar en la vida y el respeto de los demás, y que tienen un razonable sentimiento de valía y auto respeto" (Maslow, 1983, 355). Si suponemos que las necesidades básicas son las únicas motivaciones de los seres humanos itendremos que concluir que las personas en vías de autorrealización están inmotivadas? Ésta es la situación en que se encuentra el yo existencial en esta fase de su desarrollo. Es un yo autónomo, integrado, pero en el fondo no es feliz, sino desdichado. "Ha probado ya todo lo que el dominio de lo personal puede ofrecerle y no le resulta satisfactorio. El mundo ha comenzado a devenir insustancial y ninguna experiencia merece ya la pena. [...], las ha logrado todas, las ha experimentado todas y todas las ha descubierto igualmente decepcionantes" (Wilber, 1997, 263). Ya no le motiva conseguir nada para su yo; lo personal se ha convertido en algo insustancial. Por eso el mundo ha perdido su sentido, justo en la etapa en la que el yo alcanzaba sus mayores triunfos. Es un alma demasiado despierta. Es un alma preparada para abrirse a lo transpersonal.

Esta experiencia puede venir como una luz, que apenas se insinúa en el horizonte de su oscura noche, que va progresivamente amaneciendo; una luz nueva, un nuevo salto en la evolución de la conciencia, un salto dramático: el que le abre a la dimensión transpersonal de su propia identidad. En esa luz empieza a vislumbrarse un nuevo mundo y un nuevo yo.

\subsection{Concepción educativa: la educación como liberación crítica}

Éste es un proceso educativo de alto nivel, más allá de la mera socialización, que hace del hombre no ya un animal cultural, sino un ser civilizado abierto a la riqueza de la propia reconstrucción con valores culturales universalizables, compartibles, en un encuentro buscado con los demás como condición imprescindible de un encuentro más rico consigo mismo. Éste es el nivel máximo buscado hasta ahora por la educación; es el de la madurez personal, el de la autorrealización.

La educación es, en esta concepción, un proceso de eliminación de los factores externos, que impiden que cada uno llegue a ser el que realmente es. No 
se trata tanto de dirigir, de modelar, como de dejar crecer, de controlar los factores externos que afectan el desarrollo personal, se hace necesario modificar el medio para que cada uno llegue a ser el que es. Educar es, por tanto, protegernos de la socialización para abrirnos a la comprensión y obediencia de la voluntad general. La enseñanza para la libertad, y desde la libertad, supone una acción crítica, con nosotros mismos y con el mundo que nos rodea. De esta idea de libertad soporte fundamental de la educación se derivan otras dos igualmente relevantes; una la de individualidad, noción por la cual consideramos que cada cual es distinto y único, lo que hace necesario adecuar el proceso educativo a la individualidad propia de cada educando. Y otra la de actividad, papel que corresponde al educando en cuanto protagonista del proceso educativo, en el sentido de que sólo cabe educarse ejerciendo activamente las facultades del cuerpo y del espíritu, se aprende a pensar pensando, o a ser autónomo ejerciendo la autonomía, y no a través de un discurso que explique en detalle cómo se debe pensar, o ser autónomo. Así mismo, esta definición de la educación radicada en la idea de libertad afecta la concepción de la enseñanza, pues ya su fin no podrá ser transmisión de saberes más o menos bien clasificados y dispuestos para la asimilación del alumno, sino mostrar procedimientos para que el alumno pueda adquirirlos por sí mismo. Se trata menos de mostrar la verdad que de enseñar qué hacer para descubrirla.

Un grupo de habilidades de gran interés para los educadores humanísticos son las referidas a las relaciones interpersonales, al desarrollo de unas relaciones más positivas y auténticas, más felices, en el verdadero encuentro interpersonal, en el aprendizaje y enriquecimiento de los potenciales de la vida social. En esto está implicado el autoconocimiento, el desarrollo de una autoaceptación positiva, el crecimiento de nuestra vida afectiva. Estos educadores desearían ver en el currículo desarrollos que nos permitieran perfeccionar nuestra habilidad para percibir, imaginar, intuir, crear, fantasear, maravillarse, experimentar, expresarnos corporalmente... Para Maslow, la tendencia a la autorrealización es una tendencia natural, por eso no se debe forzar el desarrollo, sino facilitar el curso natural. El profesor sólo debe ayudar, es un facilitador, no un terapeuta freudiano, ni un mecánico del comportamiento.

6. ENFRENTANDO LA BRECHA EN LA CONCIENCIA. LA APERTURA A LO TRANSPERSONAL

Y A LA EDUCACIÓN COMO LIBERACIÓN TRASCENDENTE E INTEGRACIÓN SUPERIOR

Dado el espacio disponible, sólo expondremos el inicio de la apertura a lo transpersonal.

Fue el mismo Maslow el que hacia el final de su vida llamó la atención sobre las posibilidades que iban más allá de la autorrealización y en las cuales el individuo trasciende los límites habituales de la identidad y la experiencia; en las que uno progresivamente adquiere conciencia vivencial de su unidad esencial 
con todos los seres (conciencia transpersonal), que más allá de la autorrealización estaba la necesidad de autotrascendencia. En 1968 Maslow expresó lo siguiente:

Considero que la psicología humanista [...] es un movimiento de transición, una preparación para una cuarta psicología, "Superior" a ella, transpersonal, transhumana, centrada en el cosmos más que en las necesidades e intereses humanos, una psicología que irá más allá de la condición humana, de la identidad, de la autorrealización y cosas semejantes ( $c f r$. Walsh y Vaughan, 1982, 20).

Empezó a darse cuenta de esto cuando al estudiar a personas autorrealizadoras descubrió que tenían una serie de experiencias que él llamó "experiencias cumbres" (peak experiences); eran momentos en que se sintieron en lo más bello de la vida, minutos de inmensa reverencia, extrema alegría, arrebato, gloria o éxtasis, júbilo y felicidad..., durante esos momentos están ausentes dudas, temores, inhibición, tentaciones, debilidad, incluso hasta la conciencia del yo. Estas experiencias de las personas que se autorrealizan son más intensas y profundas y además más frecuentes que las de los demás sujetos. Sostuvo que estos estados eran posibles a toda persona y que, por lo tanto, no son cualidades de seres excepcionales, sino potenciales aún más elevados de la persona humana:

Este capítulo es un intento de englobar en una sola descripción algunos de estos rasgos cognoscitivos básicos de la experiencia del amor del ser, la experiencia de la paternidad, la experiencia de la naturaleza, de la inmensidad, de la mística, la percepción estética, el momento creativo, la comprensión intelectual o terapéutica, la experiencia orgástica, ciertas formas de hazañas atléticas, etc. A estos y a otros momentos de extrema felicidad y plenitud, los denominaré experiencias-cumbre (Maslow, 1979, 111-112, cfr. cap. 6).

Las investigaciones de Maslow con estas personas le hacen plantear una nueva concepción que amplía aún más la visión acerca del hombre: la teoría de la metamotivación. Una vez satisfechas estas necesidades básicas, los individuos más maduros, más plenamente humanos están ahora motivados en otros sentidos superiores, es decir, se encuentran con las metanecesidades. En estas situaciones, Maslow alinea "a estas personas junto a la concepción oriental de la salud como trascendencia del esfuerzo, el deseo o la avidez" (Maslow, 1983, 355). Estas concepciones las tenemos en el Budismo y en el Taoísmo. Estas necesidades superiores de los intrínsecos y últimos valores de bondad, belleza, verdad, perfección, unidad e integridad, trascendencia de las dicotomías, vida, unicidad, orden, justicia, simplicidad, autosuficiencia... corroboran la afirmación de Maslow de que el hombre posee naturaleza superior. Esta orientación hacia las metanecesidades muestra ya un centauro muy maduro. Tenemos delante un bello ser humano, integrado, que está trascendiendo su yo, y que por eso está en la crisis de una transición superior, la que definiría el tercer nivel de conflicto. Ese es el reto que tiene ante sí: entrar de lleno en los ámbitos transpersonales, salvar esa brecha en su conciencia. Este tercer nivel, que es en realidad el primer paso 
hacia nuestros estados superiores de desarrollo, hacia el descubrimiento de una identidad más profunda, sería nuestro primer paso en esa necesaria educación "Superior", llamémosla, educación transpersonal o educación como liberación trascendente.

La psicología transpersonal ${ }^{6}$ sostiene que la conciencia es la dimensión central de la naturaleza humana. Considera a nuestra conciencia habitual como un estado restringido por la inundación de un flujo continuo de pensamientos, recuerdos, sentimientos, deseos, proyectos... en gran parte incontrolados, que responden a nuestras necesidades. Es lo que aparece en el cuadro como "Corriente psicomental". Ésta funciona como una obstrucción, como un muro que impide la experiencia directa del yo superior. La conciencia óptima, presente como posibilidad en cualquier momento, es un estado en donde se abandona esa contracción defensiva, aquietando la mente y reduciendo la deformación perceptiva. Cuando se produce el silencio de la mente tomamos conciencia de que nuestro estado habitual no sólo conlleva una percepción deformada de la realidad, sino que además no reconoce esta deformación. Por tanto, la realidad que percibimos, al reflejar nuestro propio estado de conciencia, es sólo relativamente real (Walsh y Vaughan, 1982, 13-27). Ese estar atrapado por el contenido de nuestra conciencia (identificación de la conciencia con su contenido mental) hace definir nuestra identidad por nuestros roles, pensamientos, problemas, relaciones... que se vivencian como el sí mismo, y esto nos parece tan evidente, tan consensualmente validado, que no se nos ocurre cuestionarlo. Como decía Buda, somos lo que pensamos... con nuestros pensamientos hacemos el mundo. Si la conciencia se identifica con su contenido está viendo el mundo desde ese contenido, a través de él, todo lo interpreta desde él. La conciencia queda, así, atrapada en el condicionamiento. La realidad que ve no será más que un reflejo de esas lentes coloreadas desde las que interpreta el mundo. Así, si me siento desesperado veo el mundo sin esperanza. La identificación de mi conciencia con el sentimiento de desesperanza hace que no vea ese sentimiento, sino más bien, que lo vea todo desde él. Ese reflejo no hará más que reforzarme la perspectiva desde la que miro. De ahí que el despertar sea una desidentificación progresiva respecto de los contenidos mentales a través de la observación lúcida y desinteresada (Fdez. Herrería, 2005, 391-400) (constituye la meditación vipassana, en pali, significa "ver", "observar" con claridad). Esta observación sin juicio, ni valoraciones, que no manipula lo que ve, sino que es una atención "que fluye con lo que se esté experimentando, siguiéndolo y permitiéndole ser lo que es" (Rowan, 1996, 117-118), que se instala en la inocencia de una desprendida

6. Hay una serie de obras colectivas, otras individuales, que son introductorias, muy indicadas para tener una visión de conjunto tanto de la psicología, como de todo este movimiento transpersonal, entre las que cabe destacar las de Walsh y Vaughan (1982, 1994); Grof (1988, 1994); Almendro (1995, 1999); Rowan (1996); WeIL (1997) y que aparecen citadas en la bibliografía. 
imparcialidad, es la que nos permite "salir" del río psicomental y estar fuera observándolo. Esto supone, en la práctica, que estoy deshaciendo la obstrucción de mi conciencia por el proceso de desidentificación y que puedo empezar a sentir la enorme fuerza atractiva del yo transpersonal; es decir, se inicia un viaje sin retorno hacia la otra orilla, un viaje de autodescubrimiento en el que se cruza la brecha en mi conciencia, el desierto, entre mi yo condicionado, el personaje del teatro de la vida, y el actor, la realidad superior, un viaje muy significativo desde una identidad egoica estrecha, nuclear, aislada de los demás y del mundo, a una identidad en expansión, participativa, de campo, que se experimenta finalmente como un proceso de liberación.

Así, mientras los psicólogos humanistas estudian lo que se ha dado en llamar el nivel personal de la conciencia: en él entramos en comunicación con los demás, aunque nos sentimos separados de los otros y del mundo, los psicólogos transpersonales estudian la dimensión transpersonal de la conciencia. Ésta se refiere a aquellas experiencias en las que uno progresivamente adquiere conciencia vivencial de su unidad esencial con todos los seres, como afirma McWaters (1978, 193-197), lo que no quiere decir una disolución de la conciencia en el todo, sino un encuentro de uno mismo como una parte de ese todo. Roberts (1978, 142) afirma que mientras los psicólogos humanistas tienden más a explorar las relaciones interpersonales, los psicólogos transpersonales se interesan por las experiencias humanas más subjetivas, trascendentes y poco comunes. Si el concepto clave de la psicología humanística podría ser el de autorrealización, el de la "cuarta fuerza" es el de trascendencia. Precisamente esta psicología se llama transpersonal porque muchas de las experiencias que investiga implican una trascendencia de la personalidad, del "yo" estereotipado y conformado por el medio sociocultural. En otras palabras, el término transpersonal, tal como afirman Walsh y Vaughan $(1982,14)$ "fue adoptado [...] para referirse a los informes de personas que practican diversas disciplinas que afectan específicamente a la conciencia y que hablan de experiencias de una extensión de la identidad que va más allá de la individualidad y de la personalidad", es decir, más allá de los límites habituales del ego y de la personalidad. Al no haber estudios de estos desarrollos superiores en la psicología occidental, los psicólogos transpersonales se acercaron a las tradiciones antropológicas y espirituales orientales clásicas (India, China, Japón), las occidentales y las culturas indígenas (yoga, zen, budismo, hinduismo, sufismo, misticismo cristiano, chamanismo...) y sus sugestivos y elaborados cuadros sobre el desarrollo de estos niveles superiores, para emprender la tarea de exponerlos en el lenguaje de la ciencia a fin de sistematizar un verdadero corpus antropológico sobre el desarrollo humano completo. Las prácticas espirituales de estas tradiciones son estudiadas, experimentadas, filtradas y comparadas interpretándose como metodologías de acceso y desarrollo de los distintos estadios del mapa evolutivo humano. Desde nuestra perspectiva, son las nuevas metodologias, estrategias y técnicas educativas: las de un campo que no bemos trabajado, el campo de lo transpersonal. Esta psicología es, por consiguiente, la primera psicología 
verdaderamente intercultural. Ken Wilber es uno de sus principales representantes. Su obra extensa y compleja, traducida a más de veinte idiomas, asume esta tarea, junto con un numeroso grupo de colegas y colaboradores. Sus trabajos se plantean en una perspectiva integral ${ }^{7}$. El enfoque transpersonal-integral realiza una aproximación pluridimensional a la identidad del ser humano ofreciendo un modelo en donde la conciencia configura un amplio espectro, en un progresivo desarrollo de estados, desde el nivel en donde el ser humano reduce su identidad a sólo partes del ego, rechazando como no suyas otras, hasta la conciencia de unidad, pasando por una serie de estados intermedios. Se relacionan los diferentes estados del desarrollo humano con técnicas y metodologías generales correspondientes para cada nivel.

\section{Reflexiones finales}

A continuación presentamos las aportaciones que consideramos importantes de cara a la reconstrucción del concepto de educación que se derivan de lo dicho en este estudio:

a. Que no podemos reducir la educación, especialmente en la práctica, a un mero proceso de socialización, a pesar de su importancia, proceso instrumentalizado en último término por el mercado. La educación debe ser crecimiento, emancipación, humanización y no sólo formación para la inserción laboral.

b. Que los mapas del desarrollo humano son los mapas de la educación y que éstos no se reducen a lo cognitivo. Hay que profundizar la educación (en el sentido de Hargreaves y tantos otros), abrirla a las otras «inteligencias", a las demás líneas de desarrollo y por ello necesitamos abrir la escuela a la comunidad. Esta apertura facilitaría la profundización.

c. Que una concepción evolutiva de la educación (proceso de antropogénesis) que se inicia con el aprendizaje de la conducta humana, hasta que se enfrenta con las últimas cimas conocidas de su desarrollo, al adentrarse en los ámbitos transpersonales, implica un proceso de aprendizaje y de construcción de lo humano cada vez más rico y complejo, un desenvolvimiento constructivo de la vida en un aprendizaje cuya amplitud y profundidad impresionan, tanto que si esto lo comparamos con lo que llamamos educación y, sobre todo con su práctica, ésta queda tan perdida, reducida y desvaída que nos preguntamos

7. En su penúltima obra en castellano: Espiritualidad integral (2007), informa de la web de estos enfoques integrales: el Center for Integral Medicine, Center for Integral Leadership and Business, Center for Integral Ecology, Department of Religious Studies (www.integraluniversity.org.); sobre una Espiritualidad Integral (www.integralspiritualcenter.org); www.kenwilber.com www.integralinstitute.org. www. IntegralTraining.com. Al final de su obra Espiritualidad integral hace una relación de sus libros ordenados temporalmente, lo cual es de agradecer pues es recomendable una lectura siguiendo ese orden. 
si deberíamos seguir utilizando esa palabra. Por tanto, no se trata ya de hacer incorporaciones aisladas, que aunque importantes (p. ej. lo emocional), les falta la visión global, el contexto integral que les da sentido e inteligibilidad. Necesitamos una visión integral.

d. Tendremos que admitir que no todo es ayudar a la vida a crecer y construirse, también tenemos que ver que cuando nos mentimos de tantas maneras y tipos (tantas como niveles de desarrollo hay: patologías de nivel) y que cuando contraemos enfermedades, las propias de las diferentes etapas del desarrollo, tendremos que saber curar y encauzar por las vías correctas, la humanización sin fin. Esto implicará dos cosas: que nosotros conozcamos los caminos por propia experiencia y que tenemos que asumir que diferentes tipos de terapias (de Gestalt, terapia Cognitiva...) son formas de curar, es decir, de volver a "colocarnos" en la senda correcta de desarrollo. Resulta chocante el prejuicio del mundo educativo ante la terapia, cuando el ser humano, nada más empezar su vida, tiene ante sí las posibilidades de deslizarse en caminos insanos. Si hablamos de educación, en sentido pleno, no podemos cerrar los ojos a este tipo de situaciones. La educación debe humanizarse, tratar con la persona completa, no sólo con parte de su cabeza. Tenemos, pues, que cambiar de mentalidad y ver estas terapias como lo que son: técnicas educativas, si queremos hablar de educación verdaderamente integral.

e. Que el proceso educativo y la humanización van en la línea de un egocentrismo decreciente a la vez que una creciente interioridad; que implican procesos crecientes de trascendencia, puesto que la conciencia va continuamente desidentificándose del nivel anterior e identificándose con el nivel siguiente, con lo que integra todo el potencial de los niveles anteriores (cuando hablamos de las estructuras cognitivas), o supera esos niveles (cuando hablamos de otros niveles de desarrollo, p. ej. el juicio moral, o las necesidades del yo... En este caso un nivel no integra al anterior, así, el mundicentrismo no integra al etnocentrismo, simplemente lo supera, yendo más allá de él).

f. Esto es lo mismo que decir que el sentido de la educación implica una conciencia, un sentido de la identidad cada vez más ampliada (desde un yo identificado con el cuerpo, hasta un yo mundicéntrico y aún más allá: transpersonal), en una creciente disminución del narcisismo hasta cuotas en donde el yo se reconstruye en un sentido "universal" transpersonal.

g. Que con el avance de la humanización (antropogénesis) la educación se hace cada vez más interna, personal, más cercana a un permanente viaje de descubrimiento que deja de ser meramente personal, más sorprendente y sutil, más desligada de los procesos mentales, para deslizarse fugazmente en el silencio, en la mirada bañada por el vacío de lo conocido, en una creativa libertad y poder, en puro arte.

h. Que lo único que hace falta conseguir es encender el "fuego", no tanto llenar la "olla". Esto supone que cada educador tiene ese fuego encendido, el fuego de la única verdadera necesidad humana, la de la autorrealización. Ese fuego no 
se transmite, normalmente, llenando la cabeza de contenidos (también habrá que hacer algo de eso, pero si se enciende ese fuego, este otro aprendizaje se da por añadidura, se hace con gusto y de forma más creativa), al revés, suele embotar internamente y le hace más difícil encender su llama. Pero no nos convencemos de esto y seguimos trabajando el "llenado" y las mejores formas de hacerlo (didácticas) sin ver que sin esa urgencia interna de crecimiento sólo somos autómatas con forma externa de persona y a los autómatas se les condiciona, se les dirige y ahí se queda su "educación".

i. Reivindicamos, pues, la dimensión interior, espiritual, del ser humano, también olvidada en el sistema educativo. No es un monopolio de las religiones, sino una dimensión antropológica. El descuido educativo de esta dimensión está provocando una formación de autómatas, eso sí, altamente especializados. El intelecto sin espíritu es peligroso. Necesitamos urgentemente de una cultura interior que nos lleve hacia nuestra identidad más profunda. Vivimos de forma deshumanizada, "perdidos", alienados y "cosificados" en el mundo de las cosas como un objeto más, volcados en la pura exterioridad, incapaces de conectarnos con nuestra realidad interna, enajenados y devorados por un activismo evasivo, desconocedor de los valores de la quietud, el recogimiento y el silencio. Esto nos causa una tensión, un estrés y un vacío soterrado, denso, que nos lleva al cansancio, a la vida automatizada, a la insensibilización, a sentirnos separados y, en gran parte, insolidarios. La quiebra espiritual se produce cuando todo tiene un precio pero ya nada tiene valor. En definitiva, necesitamos, como dice Claudio Naranjo en el índice de una sus obras (2004): “Una educación de la persona entera para un mundo unificado"; "Un currículum de autoconocimiento, reeducación interpersonal y cultivo espiritual", "Educar para Ser"; "Sobre la desidentificación del ego y el reconocimiento de la esencia"... Una "nueva" filosofía de la educación, aún "fuera" de la cultura pedagógica.

\section{REFERENCIAS BIBLIOGRÁFICAS}

Almendro, M. (1995) Psicología y Psicoterapia Transpersonal. Barcelona, Kairós.

Álvarez Uria, F. y Varela, J. (1991) Arqueología de la escuela. Madrid, Endymión.

Botkin, J. M.; ElmandjRa, M. y Malitza, M. (1979) No Limits to Learning: Bridging the Human Gap: a Report to the Club of Rome. Oxford, Pergamon Press.

CAmps, V. (1994) Los valores de la educación. Madrid, Alauda/Anaya.

Castells, M. (1996) La era de la información. Economia, Sociedad y Cultura, vol. 1. La Sociedad Red. Madrid, Alianza Editorial.

De la Torre, S. y Moraes, C. (2005) Estrategias para reencantar la educación. Málaga, Aljibe.

Del Val, J. (1996) Los fines de la educación. Madrid, Siglo XXI.

Eluss, R. y McCuntok, A. (1993) Teoría y práctica de la comunicación humana. Barcelona, Paidós.

Escámez, J. y García, R. (1989) Antropología y Educación, en AA.VV. Filosofía de la Educación hoy, vol. II. Madrid, Dykinson. 
FAure, E. (1973) Aprender a ser: La educación del futuro. Madrid, Alianza/UNESCO.

Fernández Herrería, A. (2005) Mundo emocional y silencio a través de la observación lúcida, en Comunicaciones al V Congreso Internacional de Filosofía de la Educación. Madrid, Dykinson, 391-400.

Fullat, O. (1978) Filosofías de la Educación. Barcelona, Ceac.

- (1992) Filosofías de la Educación. Paideia. Barcelona, Ceac.

Goble, F. (1977) La tercera fuerza. La psicología propuesta por Abraham Maslow. México, Trillas.

Greig, S.; Pike, G. y Selby, D. (1991) Los derechos de la Tierra. Como si el planeta realmente importara. Madrid, Popular.

Grof, S. (1988) Psicología Transpersonal. Nacimiento, muerte y trascendencia en psicoterapia. Barcelona, Kairós.

- (1994) La evolución de la conciencia. Barcelona, Kairós.

Hargreaves, A. (1998) Una educación para el cambio. Barcelona, Octaedro.

- (comp.) (2003) Replantear el cambio educativo. Un enfoque renovador. Madrid, Amorrortu.

Heidenreich, M. (2003) Die Debate um die Wissensgesellschaft, en Böschen, S. y SchulzSCHAefFer, I. (eds.) Wissenschaft in der Wissensgesellschaft. Opladen, Westdeutscher Verlag.

McWaters, B. (1978) Líneas generales de la Psicología Transpersonal. Su significado y su importancia para la Educación, en RoBerTs, Th. (comp.) 4 Psicologías Aplicadas a la Educación, vol. I, 193-197.

Maslow, A. (1963) Motivación y Personalidad. Barcelona, Sagitario.

- (1978) Algunas Implicaciones Educacionales de las Psicologías Humanísticas, en Roberts, Th. (comp.) 4 Psicologias Aplicadas a la Educación, vol. II, 192-201.

- (1979) El hombre autorrealizado (3. ${ }^{a}$ ed.). Barcelona, Kairós.

- (1983) La personalidad creadora. Barcelona, Kairós.

Matson, F. (1984) Conductismo y Humanismo. ¿Enfoques antagónicos o complementarios? México, Trillas.

MOUnier, E. (1967) Introducción a los existencialismos. Madrid, Guadarrama.

Pérez Gómez, A. (1998) La cultura escolar en la sociedad neoliberal. Madrid, Morata.

Pérez TAPIAS, J. A. (1996) Claves humanistas para una educación democrática. Madrid, Alauda/Anaya.

Quitman, H. (1989) Psicología Humanistica. Barcelona, Herder.

ROBERTs, Th. (comp.) (1978) 4 Psicologías Aplicadas a la Educación, 2 vols. Madrid, Narcea.

Rogers, C. (1974) El proceso de convertirse en persona. Buenos Aires, Paidós.

- (1987) El camino del ser. Barcelona, Kairós.

Rowan, J. (1996) Lo transpersonal. Psicoterapia y Couselling. Barcelona, Los libros de la liebre de marzo.

Santos Rego, M. A. (1995) Desarrollo del pensamiento y proceso educativo: reflexiones y estrategias de optimización conjunta. Teoría de la Educación. Revista Interuniversitaria, 7, 39-51.

Savater, F. (1997) El valor de educar. Barcelona, Ariel.

TAYLOR, C. (1993) El multiculturalismo y la política del reconocimiento. México, FCE.

Toro, J. M. (2005) Educar con "co-razón". Bilbao, Desclée De Brouwer.

Walsh, R. y Vaughan, F. (eds.) (1982) Más allá del ego. Textos de Psicología Transpersonal. Barcelona, Kairós. 
- (1982) ¿Qué es una persona?, en Walsh, R. y Vaugan, F. (comps.) Más allá del ego. Barcelona, Kairós, 75-88.

- (1994) Trascender el ego. La visión transpersonal. Barcelona, Kairós.

WeIL, P. (1997) Los Límites del Ser Humano. Estados Modificados de Conciencia. Barcelona, Los libros de la liebre de marzo.

WilBer, K. (1988) Un Dios sociable. Barcelona, Kairós.

- (1989) El proyecto atman. Barcelona, Kairós

- (1991) Los tres ojos del conocimiento. Barcelona, Kairós.

- (1994) El espectro del desarrollo transpersonal, en Walsh, R. y Vaugan, F. (eds.) Trascender el ego. La visión transpersonal. Barcelona, Kairós, 202-205.

- (1997) Breve historia de todas las cosas. Barcelona, Kairós.

- (2000) Una visión integral de la Psicología. México, Alamah.

- (2005) Sexo, ecología, espiritualidad (2. ${ }^{a}$ ed. rev.). Madrid, Gaia.

- (2007) Espiritualidad integral. Barcelona, Kairós. 